\title{
Reactivation of brown adipose tissue
}

\section{By Brian R. Holloway, ICI Pharmaceuticals Division, Mereside, Alderley Park, Macclesfield, Cheshire SK10 4TG}

Brown adipose tissue (BAT) is an important regulator of energy balance in some rodent species, including the rat and mouse, at all stages of life. The high surface area:body-weight of small rodents renders them particularly vulnerable to heat loss, and BAT is the principal site of increases in compensatory thermogenesis to defend body temperature (Foster \& Frydman, 1978). The capacity of BAT for thermogenesis is dependent on a 'proton conductance' mitochondrial membrane 'uncoupling protein' (UCP) which is unique to the tissue (Nicholls $e t$ al. 1976). UCP has a high affinity for purine nucleotides, and the specific binding of GDP has been used extensively to monitor the activity of the proton conductance pathway. In the neonatal rat GDP binding is at its highest (Sundin \& Cannon, 1980). As the animal grows and requirements for compensatory thermogenesis decrease there is a parallel decline in BAT mitochondrial GDP binding which appears to plateau at between 3 and 6 weeks of age. The extent of the decline is governed by environmental temperature, dietary energy intake and genotype. Nevertheless, BAT in young adult rats retains the capacity to respond to demands for increased (or decreased) compensatory thermogenesis.

Further decreases in BAT activity take place in very old rats (12-36 months) coupled with a reduced capacity for compensatory thermogenesis (Horan et al. 1988). The amount of BAT recovered from 24-month-old rats was $30 \%$ less than from 3-month-old rats (Scarpace et al. 1988). However, identifiable BAT is present throughout life (Horan et al. 1988).

In other species the post-partum decline in BAT activity is much more rapid and complete. The neonatal guinea-pig has clearly identifiable BAT, but the activity of the tissue is reduced within a few weeks of birth such that it is more akin to white adipose tissue (WAT) (Holloway et al. 1984). Based on criteria which include multilocularity of adipocytes, mitochondrial enzyme activity, GDP binding and UCP, large amounts of BAT were also present in the newborn dog (Holloway et al. 1985; Ashwell et al. 1987). However, within 2 weeks of birth (B. R. Holloway, unpublished results) dramatic changes in the appearance and activity of the tissue take place which suggest that BAT has been replaced by WAT. Similar changes appear to take place in other species including the cat (Loncar et al. 1986) and the sheep and the cow (Casteilla et al. 1989). In the newborn calf UCP mRNA was present in all adipose tissue depots (including perirenal, pericardiac, intermuscular, mesenteric, omental and retroperitoneal) except subcutaneous. Within $5 \mathrm{~d}$ of birth UCP mRNA was no longer detectable in any depot. The rapidly diminishing role of BAT in these species parallels decreased requirements for compensatory thermogenesis due to increased body size, favourable environment, temperature and controlled intake. In some domestic species capacity for increases in compensatory thermogenesis may have been further decreased by the selective breeding of animals for increased efficiency. Despite the apparent transformation in some species of active neonate BAT to a tissue with the gross characteristics of WAT, appropriate stimuli which increase demand for thermogenesis may lead to the reactivation of the tissue. 


\section{Reactivation of $B A T$ in the rat}

The young rat clearly retains active BAT that is able to make a significant contribution to demands for increases in compensatory thermogenesis (Foster \& Frydman, 1979; Rothwell \& Stock, 1981). Increased demand for compensatory thermogenesis in the rat involves a two-phase response in the activity of BAT. The first phase is a rapid activation of the tissue by 'unmasking' existing UCP, leading to increased GDP binding. This response is elicited within 20 min of exposure to a cold $\left(+4^{\circ}\right)$ environment (Swick \& Swick, 1986a) or acute administration of a sympathomimetic substance (Milner et al. 1988). The second phase is a trophic response involving hypertrophy of BAT, increased numbers of mitochondria (Himms-Hagen, 1986) and increased synthesis of UCP (Peachey et al. 1988) as stimulated by sustained cold exposure (Desautels et al. 1978; Peachey et al. 1988), overfeeding (Rothwell \& Stock, 1979; Ashwell et al. 1984) or chronic administration of a sympathomimetic substance (Mory et al. 1984; Young et al. 1984).

Despite the decline in BAT activity in old rats (Horan et al. 1988) they still retain the ability to increase the amounts and activity of BAT in response to some but not all thermogenic stimuli. GDP binding and iodothyronine 5 '-deiodination were increased to similar levels in cold-exposed old (18-21 months) and in young ( 3 months) rats (Dullo et al. 1988). BAT mitochondrial GDP binding is also increased in relatively old (7 months) rats made hyperphagic by provision of a low-protein diet (Swick \& Swick, $1986 b)$. In contrast, unlike young ( 3 months) rats, older (6.5 months) rats did not increase BAT activity in response to overfeeding induced by a 'cafeteria diet' (Rothwell $\&$ Stock, 1983). In some circumstances the age-related decline in the activity of rat BAT is accelerated. The obese ( $f a / f a$ ) Zucker rat has a lower GDP-binding capacity than lean rats of a similar age, although there is less of a difference in concentration of UCP between genotypes (Ashwell et al. 1985; Peachey et al. 1988). The decrease in GDP binding in obese rats may be related to reduced noradrenaline turnover in the BAT of obese rats, as adrenalectomy led to a normalization of sympathetic activity (York et al. 1985) and BAT activity (Marchington et al. 1983). Cold exposure (Holt et al. 1983) also reactivates BAT in young, obese Zucker rats, although overfeeding is without effect except in adrenalectomized animals (Holt et al. 1983).

Surgical denervation of the five sympathetic nerves supplying one lobe of the interscapular brown fat leads to loss of protein, GDP binding and mitochondrial enzyme activity, whilst the intact lobe is not affected (Rothwell \& Stock, 1984). Administration of $\beta$-agonists to rats with a unilateral or a bilateral denervation of interscapular BAT reversed the decrease in activity associated with nerve sectioning (B. R. Holloway, unpublished results).

\section{Reactivation of BAT in the guinea-pig}

The adult guinea-pig lacks the rapid first phase response to thermogenic stimuli (Holloway et al. 1984). A single injection of noradrenaline or adrenaline did not increase GDP binding in mitochondria isolated from the interscapular adipose tissue of warmacclimatized guinea-pigs. Overnight cold exposure $\left(+4^{\circ}\right)$ of guinea-pigs was also without effect on mitochondrial GDP binding. Likewise infusions of noradrenaline in anaesthetized adult guinea-pigs caused only a small $\left(+0.3^{\circ}\right)$ increase in the temperature of the interscapular fat pad compared with the marked increase in temperature $\left(+1.0-1.4^{\circ}\right)$ in the neonate interscapular adipose tissue.

Unlike acute stimuli (such as overnight cold exposure) some chronic stimuli do increase the activity of the interscapular fat pad in adult animals. Daily administration of noradrenaline or adrenaline to adult guinea-pigs for 2 weeks increased mitochondrial 
protein content of the interscapular fat pad and the activity of its mitochondrial enzymes (Huttunen \& Kinnula, 1979). Sustained cold exposure for several weeks has a pronounced effect on the interscapular fat pad of adult guinea-pigs. The changes in the tissue resemble the 'second phase' or trophic response to chronic stimulation seen in the rat. The exposure of adult guinea-pigs to an environmental temperature of $+4^{\circ}$ leads to the interscapular fat pads losing the appearance of WAT and regaining that of neonate BAT. The tissue also loses weight and stored triglyceride, whilst the activity of the mitochondrial marker enzyme cytochrome $c$ oxidase $(E C$ 1.9.3.1) and the amount of mitochondrial protein are greatly increased. GDP binding is increased by cold exposure of adult guinea-pigs, although by a smaller amount than in the cold exposed rat. The interscapular fat pad temperature response to infused noradrenaline is increased in cold-acclimatized adults to a level equivalent to that in the neonate. Lastly BAT cells isolated from cold-adapted guinea-pigs exhibit an enhanced respiration response to noradrenaline compared with cells prepared from warm-acclimatized adults (Rafael $e t$ al. 1986). Therefore, chronic cold exposure of adult guinea-pigs stimulates reactivation of BAT, but when cold-exposed guinea-pigs are returned to a warm environment the activity of the tissue rapidly declines. This process begins with decreased GDP binding and remasking of UCP (Ashwell $e t$ al. 1986) and ends with loss of mitochondrial enzyme activity and accumulation of triglycerides (B. R. Holloway, unpublished results), such that the depot resembles WAT again.

\section{Reactivation of BAT in the dog}

Experiments in adult dogs indicate that the response of some adipose tissue depots to acute stimulation shares one feature which is common to rat BAT but not WAT. Infusion of anaesthetized rats with noradrenaline stimulates large increases (12 to 20-fold) in blood flow to rat interscapular BAT (Foster \& Frydman, 1978), but not to WAT depots (Wickler et al. 1982). Some adipose tissue depots in adult anaesthetized dogs exhibit similar responses to rat BAT on infusion of noradrenaline (Holloway et al. 1985). The largest increases in noradrenaline-stimulated blood flow were to axillary (64-fold), perirenal (53-fold) and intercostal (47-fold) adipose tissue depots. The smallest increase in blood flow was to the dorsal subcutaneous adipose tissue (2-fold). However, absolute noradrenaline-stimulated flow rates in dog adipose tissue are less than in rat interscapular BAT. Furthermore, measurements of oxygen extraction by bladder adipose tissue indicated that this depot contributes only a small amount to the noradrenaline-induced increase in whole-body metabolic rate, although the total adipose tissue mass may make a significant contribution. The poor $\mathrm{O}_{2}$ extraction on acute stimulation is associated with a lack of UCP in adult dog adipose tissue depots (Ashwell et al. 1987) and a lack of increased GDP binding in response to noradrenaline infusion (Holloway et al. 1985). Despite the poor response to acute adrenergic stimulation adipose tissue depots in the adult dog, like those in the guinea-pig, respond to sustained stimulation. Cold exposure of adult dogs $\left(+3^{\circ}\right.$ for 4 weeks) increased capacity for compensatory thermogenesis such that dogs did not gain weight even when fed $150 \%$ of their maintenance diet (Crist \& Romsos, 1987). Noradrenaline release in plasma and urinary noradrenaline excretion were increased in the dogs (indicating increased sympathetic activity), although there was no measurement of adipose tissue variables. Experiments in the rat demonstrated that chronic administration of $\beta$-receptor agonists mimics the effects of cold exposure, causing hypertrophy and activation of BAT (Young et al. 1984). Dosing 6-month-old dogs with LY79730 (1 mg/kg, subcutaneously twice daily for $14 \mathrm{~d}$ ), a novel compound with $\beta$-stimulant properties (Yen et al. 1983), increased resting metabolic rate and capacity for compensatory thermogenesis (Ashwell 
et al. 1987). This effect on energy expenditure was associated with the reactivation of brown fat, based on evidence which included morphological appearance, histology and on a biochemical and immunological assessment of adipose tissue activity. Adipose tissue in control, adult dogs was white in appearance and was found to be totally composed of unilocular fat cells. However, treatment with LY79730 resulted in a pronounced change in the appearance of adipose tissue depots such that they resembled brown rather than white fat. This change in gross morphological appearance was paralleled by histological changes, which included an increase in the frequency of multilocular cells. The greatest degree of multilocularity occurred in perirenal and bladder adipose tissue, and to a lesser extent in the subcutaneous depot. The average cell diameter of perirenal and bladder depot adipocytes was significantly less than in controls, but there was no significant effect of treatment on the diameter of subcutaneous adipocytes. Increased multilocularity and decreased cell diameter could merely be a consequence of lipid depletion, secondary to the lipolytic activity of the compound. However, the morphological and histological effects of treatment were accompanied by increases in total protein, cytochrome $c$ oxidase and creatine kinase ( $E C$ 2.7.3.2) activity. The specific activity of cytochrome $c$ oxidase, but not of creatine kinase, was also increased in adipose tissue depots of dogs receiving the drug compared with control animals. Site differences in enzyme levels were similar to those observed for histological changes, the greatest effect of treatment being in the perirenal depot, the smallest effect in the subcutaneous depot. Therefore, histological evidence and measurement of enzyme activities indicate that the tissue has been reactivated to a state equivalent to that in neonate BAT. Treatment also leads to an increase in the 'proton conductance' pathway which is unique to BAT. Mitochondrial GDP binding was significantly higher in treated than in control dogs. Homogenates of adult dog adipose tissue were also subjected to sodium dodecylsulphate electrophoresis and probed with a rabbit anti-guinea-pig antiserum to UCP (Ashwell et al. 1987). In electrophoretic separations of control, adult dog adipose tissue homogenates, none of the separated proteins had a detectable cross-reaction with the UCP antiserum. However, in gels from treated adult dogs, a single protein band interacted with the antiserum corresponding with the positions of purified puppy and guinea-pig UCP and equivalent to a molecular weight of 32000 . The highest concentrations of UCP were found in perirenal adipose tissue where levels ranged from 113 to $1022.2 \mu \mathrm{g} / \mathrm{g}$ tissue in samples from four treated dogs. An estimate based on values for rat UCP gives an approximate concentration of $700 \mu \mathrm{g} / \mathrm{g}$ tissue. Concentrations of UCP in puppy adipose tissue samples tended to be less than in treated adult dogs. The failure to demonstrate UCP in control adult dog adipose tissue does not exclude the possibility that it was present at low concentrations within the adipocytes. Alternatively, UCP may have been present in a small proportion of cells at high concentrations. Local foci of multilocular brown adipocytes have been demonstrated in the parametrial fat pad of cold-adapted mice, a depot which is predominantly composed of unilocular white adipocytes (Young et al. 1984). The results of experiments in the dog demonstrate that neonate BAT is replaced in the warm-acclimatized adult by a tissue resembling WAT. This process may be related to low levels of sympathetic drive, as on chronic adrenergic stimulation lipid stores are depleted, and both mitochondrial content and thermogenic activity (GDP binding and UCP concentration) are increased in parallel with enhanced capacity for non-shivering thermogenesis.

\section{Reactivation in other species}

The decline in BAT from peak activity in neonates to a WAT-like tissue probably occurs in most mammalian species. The rate of decline may be decreased by increased 
demand for compensatory thermogenesis. Cold exposure of lambs slows the transformation of neonate BAT to lipid-replete WAT-like tissue (Gemmel et al. 1972). Similarly, cold exposure of adult animals results in a reinstatement of BAT activity. Intermittent cold exposure of adult cats $\left(-30^{\circ}\right.$ for two periods of $1 \mathrm{~h} / \mathrm{d}$ for $\left.7 \mathrm{~d}\right)$ led to the reappearance of BAT (Loncar et al. 1986). Exposure to cold may also result in reactivation of BAT in adult man. Much lower concentrations of UCP were found in adults than in infants or older children (Lean et al. 1986). Exposure of adult men to cold, however, appears to be associated with enhanced activity of BAT, as judged by a histochemical assessment of adipose tissue mitochondrial activity (Huttunen et al. 1981). Increased amounts of brown fat and UCP in adult man have also been reported in conditions associated with high levels of circulating catecholamines. In a study by Lean et al. (1986) adipose tissue with the highest concentrations of UCP came from adults who died from subarachnoid haemorrhage and septicaemia. Increased amounts of very active BAT are also present in patients with phaeochromocytoma (Ricquier et al. 1982).

\section{Mechanism of reactivation}

The activity of BAT in the rat parallels sympathetic activity of the tissue (Trayhum \& Ashwell, 1987). Cold exposure and overfeeding lead to increases in sympathetic activity and BAT thermogenesis, whereas fasting and obesity lead to decreases. Decreases in sympathetic activity in BAT may also be the primary reason for the declining activity of the tissue in maturing cats, guinea-pigs, dogs and other animals. In addition, $\beta$-adrenergic receptor function diminishes with age in certain tissues (Scarpace \& Abrass, 1986). BAT from 24-month-old rats has a reduced $\beta$-receptor density and reduced adenylate cyclase ( $E C$ 4.6.1.1) response to isoprenaline, sodium fluoride and forskolin stimulation compared with tissue from 3-month-old rats. Procedures that are associated with increased sympathetic activity, including cold exposure and the administration of $\beta$-stimulants, reactivate BAT in very old rats, adult guinea-pigs and dogs. Sympathetic stimulation may accelerate the differentiation of brown adipocyte precursor cells implanted in animals (Nechad \& Olson, 1983) and cultured in vitro (Nechad et al. 1987).

\section{Conclusions}

Peak activity of BAT occurs in neonatal rats, guinea-pigs, dogs and other species. The activity of the tissue slowly declines with age in the rat, although clearly recognizable BAT is still present in senescent rats. Factors such as environmental temperature, nutrition and genetic propensity for obesity accelerate this process. In other species, including the guinea-pig and dog, the post-partum decline in activity of BAT is very rapid and complete such that the tissue resembles WAT in terms of morphology and biochemical characteristics. Nevertheless, in these species BAT may be reactivated by stimuli that increase demand for compensatory thermogenesis and restore sympathetic activity in the tissue.

\section{REFERENCES}

Ashwell, M., Holt, S. J., Jennings, G., Stirling, D. M., Trayhurn, P. \& York, D. A. (1985). FEBS Letters 179, 233-237.

Ashwell, M., Jennings, G., Stirling, D. M. \& Trayhurn, P. (1986). Biochemical Society Transactions 14, 283-284.

Ashwell, M., Rothwell, N. J., Stirling, D. M., Stock, M. J. \& Winter, P. D. (1984). Proceedings of the Nutrition Society 43, 148A.

Ashwell, M., Stirling, D. M., Freeman, S. \& Holloway, B. R. (1987). International Joumal of Obesity 11, 357-365. 
Casteilla, L., Champigny, O., Bouillaud, F., Robelin, J. \& Ricquier, D. (1989). Biochemical Journal 257, 665-671.

Crist, K. A. \& Romsos, D. R. (1987). Journal of Nutrition 117, 1280-1286.

Desautels, M., Zaror-Behrens, G. \& Himms-Hagen, J. (1978). Canadian Journal of Biochemistry 56, $378-383$.

Dullo, A. G., Kaplan, M. M. \& Young, J. B. (1988). Clinical Research 36, 480A.

Foster, D. C. \& Frydman, M. L. (1978). Canadian Journal of Physiology and Pharmacology 56, 110-122.

Foster, D. C. \& Frydman, M. L. (1979). Canadian Journal of Physiology and Pharmacology 57, $257-270$.

Gemmel, R. T., Bell, A. V. \& Alexander, G. (1972). American Journal of Anatomy 133, 143-164.

Himms-Hagen, J. (1986). In Brown Adipose Tissue, pp. 214-268 [P. Trayhurn and D. G. Nicholls, editors]. London: Edward Amold.

Holloway, B. R., Davidson, R. G., Freeman, S., Wheeler, H. \& Stribling, D. (1984). International Journal of Obesity 8, 295-303.

Holloway, B. R., Stribling, D., Freeman, S. \& Jamieson, L. (1985). International Journal of Obesity 9, $423-432$.

Holt, S., York, D. A. \& Fitzsimmons, J. T. R. (1983). Biochemical Journal 214, 215-223.

Horan, M. A., Little, R. A., Rothwell, N. J. \& Stock, M. J. (1988). Experimental Gerontology 23, $455-462$.

Huttunen, P., Hittonen, J. \& Kinnula, V. (1981). European Journal of Physiology 46, 339-345.

Huttunen, P. \& Kinnula, V. (1979). Comparative Biochemistry and Physiology 63C, 13-16.

Lean, M. E. J., James, W. P. T., \& Trayhurn, P. (1986). Clinical Science 71, 291-297.

Loncar, D., Bedrica, L., Mayer, J., Cannon, B., Nedergaard, J., Afzelius, B. A. \& Svajger, A. (1986). Journal of Ultrastructure and Molecular Structure Research 97, 119-129.

Marchington, D., Rothwell, N. J., Stock, M. J. \& York, D. A. (1983). Journal of Nutrition 113, $1395-1402$.

Milner, R. E., Wilson, S., Arch, J. R. S. \& Trayhurn, P. (1988). Biochemical Journal 249, 759-763.

Mory, G., Bouillaud, F., Combes-George, M. \& Ricquier, D. (1984). FEBS Letters 166, 393-396.

Nechad, M., Nedergaard, J. \& Cannon, B. (1987). American Journal of Physiology 253, C889-C894.

Nechad, M. \& Olson, L. (1983). Biology of the Cell 48, 167-174.

Nicholls, D. G. (1976). European Journal of Biochemistry 62, 223-228.

Peachey, T., French, R. R. \& York, D. A. (1988). Biochemical Journal 249, 451-457.

Rafael, J., Fesser, W. \& Nicholls, D. G. (1986). Biochemical Society Transactions 14, 282-283.

Ricquier, D., Nechad, M. \& Mory, G. (1982). Journal of Clinical Endocrinology and Metabolism 54, 803-807.

Rothwell, N. J. \& Stock, M. J. (1979). Nature 281, 31-35.

Rothwell, N. J. \& Stock, M. J. (1981). Pfiugers Archiv 389, 237-262.

Rothwell, N. J. \& Stock, M. J. (1983). International Journal of Obesity 7, 583-589.

Rothwell, N. J. \& Stock, M. J. (1984). Journal of Physiology 355, 457-463.

Scarpace, P. J. \& Abrass, I. B. (1986). Mechanisms of Ageing and Development 35, 255-264.

Scarpace, P. J., Mooradian, A. D. \& Morley, J. E. (1988). Journal of Gerontology 43, B65-B70.

Sundin, U. \& Cannon, B. (1980). Comparative Biochemistry and Physiology 65B, 463-471.

Swick, A. G. \& Swick, R. W. (1986a). American Journal of Physiology 251, E192-E195.

Swick, A. G. \& Swick, R. W. (1986b). American Journal of Physiology 251, E438-E441.

Trayhurn, P. \& Ashwell, M. (1987). Proceedings of the Nutrition Society 46, 135-142.

Wickler, S. J., Horwitz, B. A. \& Stern, J. S. (1982). International Journal of Obesity 6, 481-490.

Yen, T. T., McKee, M. M., Stam, N. B. \& Berris, G. (1983). Life Sciences 32, 1515-1522.

York, D. A., Marchington, D., Holt, S. J. \& Allars, J. (1985). American Joumal of Physiology 249, E299-E305.

Young, P., Wilson, S. \& Arch, J. R. S. (1984). Life Sciences 34, 1111-1117. 